\title{
What information shapes and shifts people's attitudes about capital punishment?
}

\author{
Olivia Miske (omiske@ asu.edu) \\ School of Social and Behavioral Sciences, Arizona State University \\ Phoenix, AZ, USA \\ N. J. Schweitzer (njs@asu.edu) \\ School of Social and Behavioral Sciences, Arizona State University \\ Phoenix, AZ, USA \\ Zachary Horne (Zachary.Horne@asu.edu) \\ School of Social and Behavioral Sciences, Arizona State University \\ Phoenix, AZ, USA
}

\begin{abstract}
Although most Americans support capital punishment, many people have misconceptions about its efficacy and administration (e.g., that capital punishment deters crime). Can correcting people's inaccurate attitudes change their support for the death penalty? If not, are there other strategies that might shift people's attitudes about the death penalty? Some research suggests that statistical information can correct misconceptions about polarizing topics. Still, statistics might be irrelevant for some people because they may support capital punishment for purely retributive reasons, suggesting other argumentative strategies may be more effective. In Studies 1 and 2, we examined what attitudes shape endorsement of capital punishment and compared how two different interventions shifted these attitudes. Altogether, our findings suggest that attitudes about capital punishment are based on more than just retributive motives, and that correcting misconceptions related to its administration reduces support for capital punishment.
\end{abstract}

Keywords: capital punishment; coherence; open science

\section{Introduction}

In October 2018, Washington state became the 20th state to overturn capital punishment on the grounds that it is unconstitutional, stating that death sentences have been "imposed in an arbitrary and racially biased manner" (Johnson, 2018). Although capital punishment has come under scrutiny at the state-level, a recent poll indicated that $55 \%$ of adults in the United States still favor the death penalty for a person convicted of murder (Jones, 2017). However, many people who support the use of capital punishment have misconceptions about its efficacy and administration. For instance, many people believe that capital punishment is an effective deterrent against violent crime, that innocent people are not sentenced with the death penalty, and that it is administered in a fair and unbiased manner (see Manski \& Pepper, 2013; DPIC, 2018; Baldus, Woodworth, Zuckerman, \& Weiner, 1998). The Death Penalty Information Center (DPIC) and the Innocence Project have publicly impugned these assumptions to better educate the public by releasing informational brochures and short educational videos. Given that people have misinformed attitudes about issues integral to the administration and efficacy of capital punishment, can correcting their misconceptions shift their support for the death penalty, and if not, are there other argumentative tactics that could be used to shift people's attitudes about the death penalty?

Ideally, we could affect attitude change by simply providing people with accurate statistical information - on the basis of this information, people may still support the death penalty, but it would not be based on misconceptions about its efficacy and administration. On the other hand, there is some reason to think that statistics-interventions like these may not be effective at changing people's moral attitudes. In a now classic study, Lord, Ross, and Lepper (1979) found that when people were presented with statistical evidence about capital punishment - especially when that evidence was "mixed" (providing some evidence consistent with and inconsistent with the death penalty) - this led to belief polarization. People who were strongly opposed to or strongly in favor of the death penalty attended to the information that confirmed their position and ignored the information that was inconsistent with their position. These results have led many researchers to conclude that providing statistical information is not an effective tactic for correcting people's misconceptions (e.g., Thaler \& Sunstein, 2008; Janis \& King, 1954; Gawronski \& Bodenhausen, 2006).

More recently, however, some research suggests that statistical information, especially when carefully presented (e.g., using visual aids) can correct misconceptions about polarizing topics like climate change and anti-vaccine attitudes (see Lewandowsky, Ecker, Seifert, Schwarz, \& Cook, 2012; Horne, Powell, Hummel, \& Holyoak, 2015). These results are some cause for optimism, but they do not establish exactly what interventions are most effective at changing people's attitudes about the death penalty. For example, statistics might be irrelevant to some people's support of capital punishment. For moral reasons alone, people may support the use of capital punishment, not because they believe it deters crime or is more cost effective, but because they think criminals should get what they deserve and that it is the morally right thing to do. Consequently, providing statistics about deterrence, cost, wrongful convictions, and other relevant issues may do little to alter these attitudes about the death penalty.

Current research suggests that even if attitudes about the 
death penalty are driven entirely by the desire for retribution, or because it is perceived as the right thing to do, it may still be possible to shift their moral attitudes. A recent line of work has examined how moral attitudes change when related attitudes are manipulated (e.g., Horne, Powell, \& Hummel, 2015; Holyoak \& Powell, 2016). In the law, coherence is an important theoretical virtue (e.g., Dancy, 1984). Moral theories that are incoherent are generally considered "nonstarters" and inconsistencies in influential moral theories are often the topics of entire books (e.g., Lyons, 1965; Gewirth, 1978; Rawls, 1980; Sen \& Williams, 1982; MacIntyre, 2007). These considerations do not appear to only be the concern of academics. For example, Horne and colleagues (2015) found that when people are presented with a situation (e.g., a moral dilemma) that elicits a judgment inconsistent with a general moral principle (e.g., utilitarianism), tension arises due to an internal conflict among participants' attitudes about the dilemma and the general moral principle. This tension induces belief revision because people desire to restore coherence in their network of attitudes (e.g., Festinger, 1962; Holyoak \& Powell, 2016). We call this a coherence-based intervention.

Altogether, people may support the use of capital punishment for reasons like deterrence and the cost of execution, which may suggest that presenting accurate statistical information could change people's minds (e.g., Cochran \& Chamlin, 2005). On the other hand, the death penalty is a moral issue importantly linked to attitudes about just desserts-this may suggest that coherence-based interventions would be more persuasive than raw statistical information.

In the present studies, we sought to answer two questions: First, what kinds of interventions-statistics or coherencebased-will shift people's support for capital punishment? Second, what might this tell us about what attitudes are most malleable and most central to people's endorsement of the death penalty? In Study 1, we compared the efficacy of two interventions by investigating how statistics versus coherencebased interventions changed people's attitudes about capital punishment. However, because we have reason to think that the effectiveness of these distinct arguments likely depends on the reasons people have for supporting capital punishment, and because of our results in Study 1, we sought to investigate what other related attitudes might be predictive of support for the death penalty in Study 2.

\section{Study 1}

\section{Method}

Preregistration The data collection plan, predictions, and analysis scripts for our study were preregistered through the Open Science Framework. Data, analyses, and supplemental materials are available at https://osf.io/ek4fh/.

Participants We recruited 504 participants through Amazon Mechanical Turk. Our sample size was determined by conducting a power analysis to detect a Cohen's $d$ of .25 with $80 \%$ power. We used an optional stopping procedure by computing a Bayes Factor on the parameter estimating the effect of condition (that is, the parameter of interest). Specifically, we determined that we would continue data collection until the Bayes Factor $\left(B F_{10}\right)$ was greater than 100 or less than .01 , at which point we would stop data collection (Rouder, 2014). After excluding participants who failed attention checks, 405 participants remained for our final sample ( $46 \%$ female, $M_{\text {age }}=36$ years old). Each participant was compensated $\$ 0.70$ for completing the study.

Procedure We developed statistics and coherence-based interventions aimed at countering three common attitudes people have for supporting the death penalty. These attitudes were: (1) People who commit serious crimes, such as murder, deserve to be put to death (retribution), (2) The death penalty discourages people from committing crime (deterrence), and (3) The death penalty is cheaper than life-imprisonment (cost). Participants were randomly assigned to either the statistics or coherence-based intervention, in which they saw either three statistical arguments or three coherence-based arguments in a between-subjects design.

The study proceeded as follows: Participants first were asked to rate how much they agree with three pretest statements (one statement for each commonly-held belief about capital punishment). Then participants received either the statistics or coherence-based intervention, which consisted of statistical or coherence-based arguments designed to counter attitudes about deterrence, cost, and retribution as motivations for supporting the death penalty. After reading these arguments, participants completed the post-intervention measure which captured participants' attitudes about retribution, deterrence, and cost, and their overall attitudes towards capital punishment. Participants then were asked to provide general demographic information. These measures and interventions are described in more detail below. Complete materials for this study can be found in the Supplementary Online Materials (SOM).

Pretest Measure Participants were asked to rate their agreement with three pretest statements about the death penalty. Each of these statements measured three common motivations for supporting the death penalty on a 7-point Likert scale ( $1=$ Strongly disagree, $7=$ Strongly agree $)$. For example, the item that measured attitudes about deterrence was, "The death penalty makes criminals think twice before committing murder." These statements were developed based on our post-intervention capital punishment measure.

Interventions As noted, participants were randomly assigned to either the statistics or coherence-based intervention, in which they read three statistical arguments or three coherence-based arguments against each belief for supporting the death penalty.

The statistics intervention was composed of brief summaries of empirical research taken from the Death Penalty Information Center (DPIC). This research contradicts 
common misconceptions about capital punishment. For instance, the statistical argument for deterrence summarized information about criminology experts' and researchers' conclusions regarding the efficacy of capital punishment as a deterrent. Excerpts from this argument stated that " $88 \%$ of these experts rejected the notion that the death penalty acts as a deterrent to murder", and that "studies claiming that the death penalty has a deterrent effect on murder rates are fundamentally flawed."

The coherence-based intervention consisted of brief persuasive arguments adapted from widely-cited law papers. In these papers, authors attempt to persuade readers through coherence-based arguments why the typical reasons taken to support the death penalty are inconsistent with other attitudes they otherwise strongly hold. Therefore, these arguments did not provide information about a belief being objectively false, but rather demonstrated ways in which the reason underlying a belief was incoherent with their other attitudes. For example, the coherence-based argument for cost demonstrated that determining whether someone should live or die based off of financial considerations is not a practice people generally condone and thus, it should not be considered a good reason in the case of capital punishment either. For complete intervention materials, see Table S2 and S3 in the SOM.

Posttest Measure The posttest items measured participants' attitudes about retribution, deterrence, and cost, along with their attitudes towards the death penalty in general. Participants were asked how much they agreed with 13 statements, adapted from the Death Penalty Attitudes Questionnaire (O’Neil, Patry, \& Penrod, 2004). An example of a general death penalty item (general items labeled G1 G4 in Figure 2) was, "I think the death penalty is necessary." Other items concerned attitudes about retribution (labeled R1 R4 in Figure 2), deterrence (labeled D1 - D3), and the cost of the death penalty (labeled C1 - C2). For example, one item was "Society has a right to get revenge when murder has been committed."

\section{Results}

We tested whether statistical or coherence-based arguments would be more effective at changing people's attitudes towards capital punishment. Further, we aimed to understand how the effectiveness of each intervention varied as a function of the specific attitudes, or reasons people have for supporting capital punishment. In order to test this, we performed Bayesian ordinal mixed-effects modeling, predicting post-intervention attitudes towards the death penalty on the basis of condition ( $1=$ statistics, $0=$ coherence-based), and participants' pretest attitudes, which we modeled as a monotonic effect. This model treated both participants and scale items as group-level effects, allowing for heterogeneity in the intercept for each participant and question. The model is specified in the syntax of brms (Bürkner, 2018):

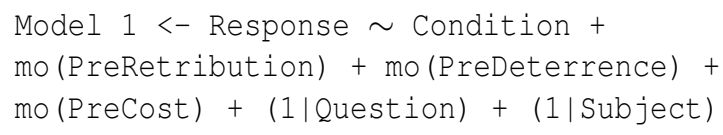

Bayesian analyses formulate model parameters as probability distributions wherein the posterior distribution for a parameter $\theta$ is computed via the prior and the likelihood of $\theta$. To model the joint probability distribution of responses, we specify regularizing priors over the possible effects each parameter could have on the response variable. Model 1 priors are shown below:

$$
\begin{aligned}
& \beta_{\text {Intercept }[1]} \sim \mathcal{N}(2.19,1) \\
& \beta_{\text {Intercept }[2]} \sim \mathcal{N}(2.94,1) \\
& \beta_{\text {Intercept }[3]} \sim \mathcal{N}(3.17,1) \\
& \beta_{\text {Intercept }[4]} \sim \mathcal{N}(3.47,1) \\
& \beta_{\text {Intercept }[5]} \sim \mathcal{N}(3.89,1) \\
& \beta_{\text {Intercept }[6]} \sim \mathcal{N}(4.59,1) \\
& \beta_{\forall \text { Pretest Beliefs }} \sim \mathcal{N}(6,1) \\
& \beta_{\text {Condition }} \sim \mathcal{N}(0,1)
\end{aligned}
$$$$
\text { Group-level effects } \sim t(3,0,10)
$$

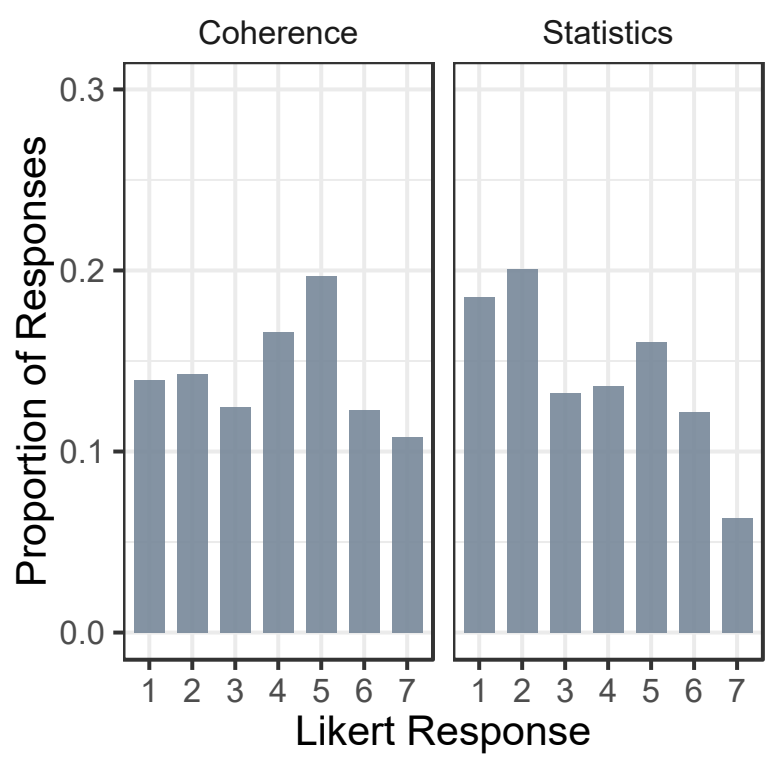

Figure 1: A histogram of the proportion of responses at a given Likert scale point $(1=$ Strongly disagree, $7=$ Strongly agree) in the Coherence and Statistics conditions in Study 1. The figure indicates that participants were less likely to agree with pro-death penalty statements in the Statistics condition than the Coherence condition.

This analysis revealed that the statistics intervention reduced overall support for the death penalty relative to the coherence-based intervention, $b=-0.58$, 95\% CI $[-0.80$, -0.35 ], $B F_{10}>100$ (see Figure 1). Models interacting pretest beliefs with condition did not account for additional variance. 


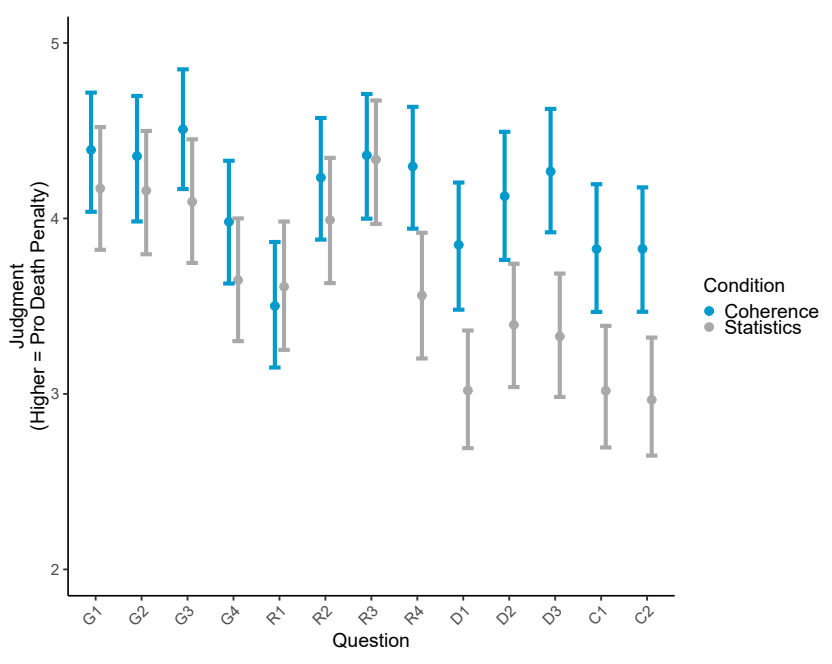

Figure 2: Death penalty attitudes for each scale item in the Coherence and Statistics conditions. Both conditions presented arguments against pro-death penalty beliefs. Error bars represent $95 \%$ Credible Intervals. Participants in the Statistical condition were less likely to endorse the death penalty than participants in the Coherence condition, but this effect varied as function of the question under consideration.

Next we investigated how condition interacted with the question to examine whether the statistics intervention affected some reasons for supporting the death penalty more than others. This model is specified below:

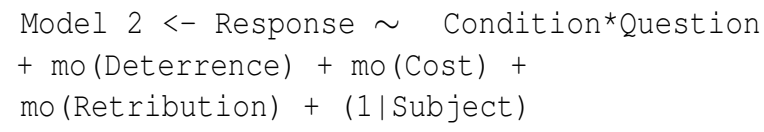

Model 2 Priors:

$$
\begin{aligned}
& \beta_{\text {Intercept }[1]} \sim \mathcal{N}(2.19,1) \\
& \beta_{\text {Intercept }[2]} \sim \mathcal{N}(2.94,1) \\
& \beta_{\text {Intercept }[3]} \sim \mathcal{N}(3.17,1) \\
& \beta_{\text {Intercept }[4]} \sim \mathcal{N}(3.47,1) \\
& \beta_{\text {Intercept }[5]} \sim \mathcal{N}(3.89,1) \\
& \beta_{\text {Intercept }[6]} \sim \mathcal{N}(4.59,1) \\
& \beta_{{ }_{\text {Pretest Beliefs }}} \sim \mathcal{N}(6,1) \\
& \beta_{\text {Condition }} \sim \mathcal{N}(0,1) \\
& \beta_{{ }_{\text {Questions }}} \sim \mathcal{N}(0,3) \\
& \beta_{\forall \text { Condition } \times \text { Question Interactions }} \sim \mathcal{N}(0,1) \\
& \text { Group-level effects } \sim t(3,0,10)
\end{aligned}
$$

The analysis interacting question with condition indicated that the statistics intervention was more effective at changing people's general death penalty attitudes (i.e., G1 - G4), people's attitudes about the efficacy of capital punishment at deterring crime (D1 - D3), and the cost of capital punishment (C1 - C2) compared to retributive attitudes (R1 - R4), $B F_{10}>$ 100, (see Figure 2). This result is consistent with the intuition that for some attitudes, perhaps those that are particularly moral in nature, statistical information is irrelevant. When predicting only general attitudes towards the death penalty on
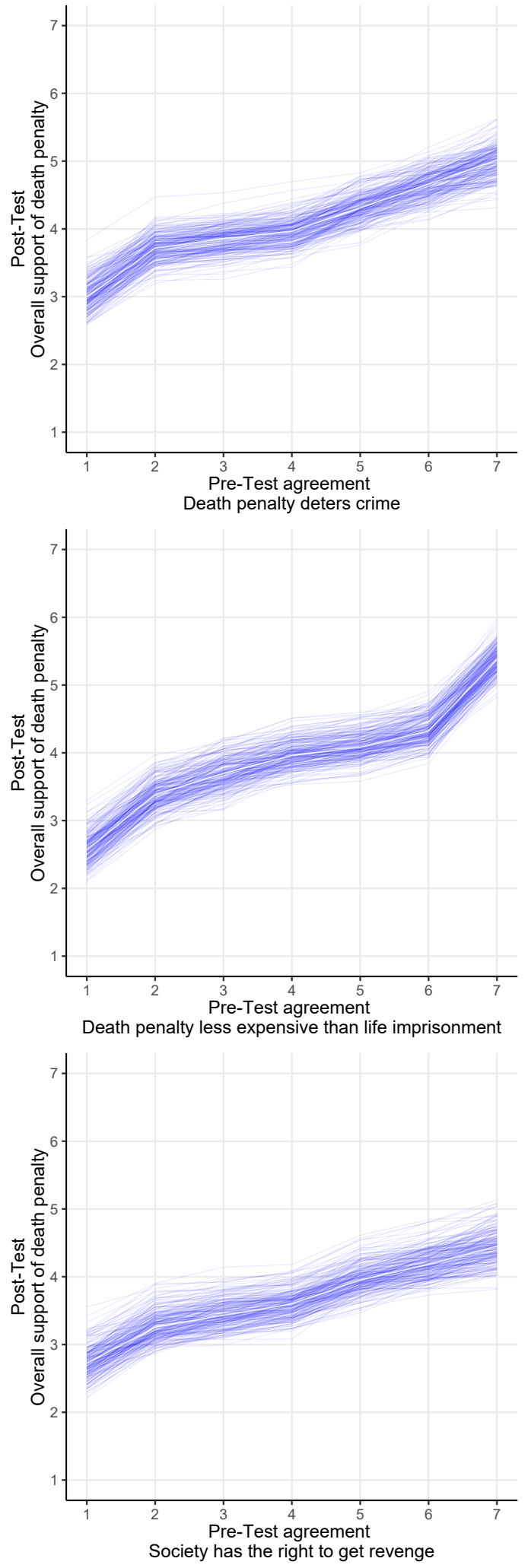

Figure 3: Spaghetti plot of post-test death penalty attitudes predicted by pre-test deterrence (top), cost (middle), and retribution (bottom) attitudes, which were treated as monotonic effects. Each regression line represents a draw from the posterior distribution. 
the basis of condition, statistics were still more effective than coherence-based interventions, $b=-0.49$, 95\% CI $[-0.88$, $-0.08]$.

The nature of our design prohibited us from testing how effective each intervention was at changing every posttest death penalty attitudes because we could not compute a difference score for every item. However, three items were repeated across pretest and posttest. Therefore, we examined whether the coherence-based condition affected these items and how these change scores compared to the statistics condition. This analysis revealed that the statistics and the coherence conditions both decreased posttest endorsement for the three pro-death penalty beliefs, $M=-0.68,95 \% \mathrm{CI}$ $[-0.78,-0.57]$ and $M=0.25,95 \%$ CI $[-0.35,-0.16]$, respectively. However, for these items alone the statistics intervention was still more effective than the coherence-based intervention.

We followed up on these analyses by conducting a series of exploratory analyses examining how deterrence, cost, and retribution attitudes predicted overall posttest death penalty attitudes. This model regressed posttest death penalty attitudes on each pretest question, allowing us to measure the unique relationship each attitude accounts for in predicting posttest attitudes. Because of the ordinal nature of our predictors, we again treated each as a monotonic effect. These analyses indicated - to our surprise - that attitudes about the cost of the death penalty ( $b=3.65,95 \%$ CI $[3.11,4.18])$ was more strongly related to people's death penalty attitudes than were beliefs about deterrence $(b=2.52,95 \%$ CI [2.01, 3.03]) and the desire for retribution, $b=2.16,95 \%$ CI $[1.60,2.73]$ (see Figure 3). Given that cost attitudes are most easily targeted by statistics interventions, and that these interventions proved more effective than a coherence-based intervention, this is further evidence that policy makers interested in shifting attitudes towards the death penalty might focus on the relevant statistics rather than moral imperatives.

Still, the results of Study 1 raised questions about what attitudes, beyond those that have been previously assumed to be relevant, are most strongly related to overall death penalty attitudes. Previous research assessing people's views about the death penalty have predominantly focused on people's retributive and utilitarian motives (i.e., people's desire for retribution and belief in the deterrent effect of capital punishment). Furthermore, some studies have used only a few items or a single dichotomous item to measure death penalty attitudes, even though public opinion polls and other research have shown that people's attitudes about this issue are complex and often dependent on the circumstances of the situation (e.g., Murray, 2003; Roberts \& Stalans, 1997). Consequently, relatively simple measures such as these are unlikely to provide substantial insight into why people endorse the death penalty, and what beliefs and motivations underlie their attitudes. This is not to deny that attitudes about retribution and deterrence are central in shaping their attitudes about capital punishment. Rather, in Study 2, we aimed to understand what other understudied factors might also play a significant role in shaping people's attitudes towards capital punishment. For instance, people may not be familiar with the rate at which innocent people are sentenced to death, or they might not know that most other industrialized countries have abolished the death penalty. If these beliefs are related to support for capital punishment, and could also be changed more easily than beliefs about retribution, then researchers could develop more effective interventions using this information (Powell, Weismann, \& Markman, 2018).

\section{Study 2}

In Study 2, we tested what attitudes are most strongly related to people's general support of the death penalty-what are the most relevant reasons people support capital punishment? We conducted an exploratory correlational study examining the relationship between previously-theorized attitudes (e.g., retribution and deterrence, Finckenauer, 1988; Carlsmith, Darley, \& Robinson, 2002) and other understudied attitudes (e.g., the importance of wrongful convictions and perceptions of execution methods) that we hypothesized may be most strongly related to people's general death penalty attitudes.

\section{Method}

Preregistration Our sample size and study materials were preregistered through the Open Science Framework at https://osf.io/ek4fh/.

Participants We recruited 249 participants through Amazon Mechanical Turk. After excluding participants who failed attention checks, 184 participants remained for our final sample ( $45 \%$ female, $M_{\text {age }}=37$ years old). Participants were paid $\$ 0.70$ for participating in the study.

Procedure Participants were asked to rate how much they agreed with statements which composed 12 scales about capital punishment, the criminal justice system, and other related topics. These attitudes are described in more detail below. After answering these questions, participants provided demographic information.

Death Penalty Attitudes Measure We measured 11 attitudes (54 items total) that we hypothesized would be relevant to people's death penalty attitudes, many of which were suggested by previous studies but not included in most death penalty measures. We again measured attitudes about retribution, deterrence, and cost. The other attitudes we included were: (1) Providing rehabilitation programs for offenders is a good idea (Rehabilitation), (2) Innocent people are sometimes sentenced to death and this is a major concern with using the death penalty (Innocence), (3) People who are wrongfully convicted of serious crimes must have done something wrong to be in that situation (Victim Blame), (4) The death penalty is barbaric (Barbarity), (5) The United States has a great deal of crime (Crime), (6) America's execution methods are humane (Humane), (7) Other countries similar to America have the death penalty (Common), and (8) 
Torture is acceptable in some cases (Torture). Our scales and items were adapted from the Death Penalty Attitudes Questionnaire (O'Neil et al., 2004), the Violence-Related Attitudes and Beliefs Scale (Brand \& Anastasio, 2006), and a study by Jiang and colleagues (Jiang, Lambert, Wang, Saito, \& Pilot, 2010). Participants rated how much they agreed with each statement on a 7-point Likert scale $(1=$ Strongly disagree, 7 = Strongly agree; Cronbach's $\alpha$ for all scales were $>$.70). For the complete list of materials and scales, see the SOM.

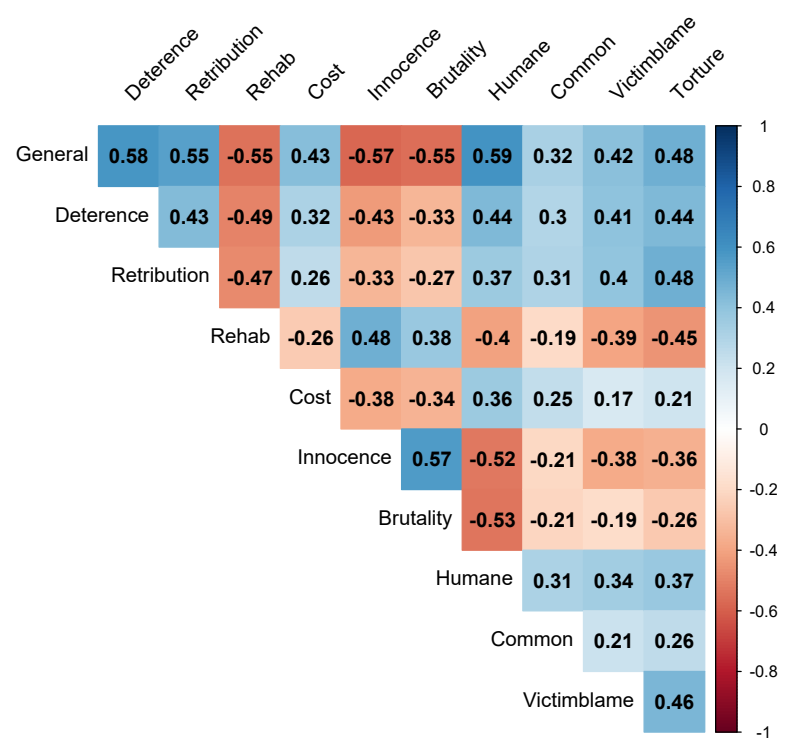

Figure 4: Kendall's tau correlation coefficients of death penalty attitudes in Study 2. Shades of blue indicate a positive correlation and shades of red indicate a negative correlation between two attitudes.

\section{Results}

We predicted that each of the 11 attitudes measured would be related to people's overall support for capital punishment, and as expected, all attitudes were correlated with participants' overall death penalty attitudes (see Figure 4). Deterrence, retribution, and the importance of innocence were among the most highly correlated attitudes with general endorsement of the death penalty. However, other attitudes exhibited surprisingly strong relationships with general support of the death penalty as well. For example, participants who endorsed the death penalty were also more likely to think that exonerated people were still nonetheless guilty or partially responsible for them being wrongfully convicted (Victim Blame; $\tau_{b}=.42$ ). Strikingly, $28 \%$ of participants agreed, at least somewhat, with the idea that wrongfully convicted people on death row were responsible for their conviction $(>4$ = Somewhat agree). Taken together, these results suggest that support for capital punishment may be more multidimensional than initially thought and provide further guidance for the development of interventions for correcting misconceptions about the administration of capital punishment.

\section{General Discussion}

Over half of the United States supports the use of the death penalty today yet are unaware of the statistics surrounding the deterrent effects and cost of the death penalty. Furthermore, there have been few systematic investigations of the attitudes, both proximal and remote, that may shape people's support for the death penalty. In Study 1, we examined how different types of interventions shift people's attitudes about the death penalty. We found that statistics interventions reduced support for the death penalty, and that these effects were largest for general death penalty attitudes, and attitudes about cost and deterrence. Furthermore, we found that statistics interventions were ineffective at changing attitudes motivated by retribution. Because retribution falls unambiguously within in the moral domain, people likely think statistics are irrelevant to the questions of whether criminals should get what they deserve. Study 1 also revealed that retribution is not the only relevant factor driving people's death penalty attitudes-beliefs about deterrence and cost were also strong predictors of overall endorsement of the death penalty. The results of Study 1 led us to examine what other attitudes, which have perhaps gone unexplored, may shape attitudes towards the death penalty (Powell et al., 2018). Study 2 revealed that many relatively "remote" attitudes were strongly correlated with endorsement of the death penalty. Of note, we observed a relationship between general death penalty attitudes and the belief that people wrongfully sentenced are to some degree responsible for their wrongful imprisonment. From an interventionist perspective, Study 2 also uncovered that many of the attitudes associated with support for the death penalty-for instance, beliefs about innocence and commonality_can be directly addressed by citing statistics. No moral imperative is required. Altogether, these findings highlight new avenues by which researchers can correct and shift people's attitudes about the death penalty.

\section{References}

Baldus, D., Woodworth, G., Zuckerman, D., \& Weiner, N. (1998). Racial discrimination and the death penalty in the post-Furman era: An empirical and legal overview with recent findings from Philadelphia. Cornell L. Rev., 83, 1638.

Brand, P. A., \& Anastasio, P. A. (2006). Violence-related attitudes and beliefs: Scale construction and psychometrics. Journal of Interpersonal Violence, 21(7), 856-868.

Bürkner, P. (2018). Advanced Bayesian multilevel modeling with the R package brms. The R Journal, 10(1), 395-411.

Carlsmith, K., Darley, J., \& Robinson, P. (2002). Why do we punish? Deterrence and just deserts as motives for punishment. Journal of Personality and Social Psychology, 83(2), 284-299.

Cochran, J., \& Chamlin, M. (2005). Can information change public opinion? Another test of the Marshall hypotheses. Journal of Criminal Justice, 33(6), 573-584. 
Dancy, J. (1984). On coherence theories of justification: Can an Empiricist be a Coherentist? American Philosophical Quarterly, 21(4), 359-365.

Death Penalty Information Center. (2018, February 23). Facts about the death penalty [PDF file]. Retrieved from https: / / deathpenaltyinfo.org/

Festinger, L. (1962). A theory of cognitive dissonance. (Vol. 2). Stanford, CA: Stanford University Press.

Finckenauer, J. (1988). Public support for the death penalty: Retribution as just deserts or retribution as revenge? Justice Quarterly, 5(1), 81-100.

Gawronski, B., \& Bodenhausen, G. V. (2006). Associative and propositional processes in evaluation: An integrative review of implicit and explicit attitude change. Psychological Bulletin, 132(5), 692-731.

Gewirth, A. (1978). Reason and morality. Chicago, IL: University of Chicago Press.

Holyoak, K., \& Powell, D. (2016). Deontological coherence: A framework for commonsense moral reasoning. Psychological Bulletin, 142(11), 1179-1203.

Horne, Z., Powell, D., \& Hummel, J. (2015). A single counterexample leads to moral belief revision. Cognitive Science, 39(8), 1950-1964.

Horne, Z., Powell, D., Hummel, J., \& Holyoak, K. (2015). Countering antivaccination attitudes. Proceedings of the National Academy of Sciences, 112(33), 10321-10324.

Janis, I., \& King, B. (1954). The influence of role playing on opinion change. The Journal of Abnormal and Social Psychology, 49(2), 211-218.

Jiang, S., Lambert, E. G., Wang, J., Saito, T., \& Pilot, R. (2010). Death penalty views in China, Japan and the U.S.: An empirical comparison. Journal of Criminal Justice, $38(5), 862-869$.

Johnson, K. (2018, October 11). Washington state supreme court deems death penalty unconstitutional. The New York Times. Retrieved from https: / / www . nytimes.com/

Jones, J. M. (2017, October 26). U.S. death penalty support lowest since 1972. Gallup Poll. Retrieved from https:// www. gallup.com/home.aspx

Lewandowsky, S., Ecker, U., Seifert, C., Schwarz, N., \& Cook, J. (2012). Misinformation and its correction: Continued influence and successful debiasing. Psychological Science in the Public Interest, 13(3), 106-131.

Lord, C., Ross, L., \& Lepper, M. (1979). Biased assimilation and attitude polarization: The effects of prior theories on subsequently considered evidence. Journal of Personality and Social Psychology, 37(11), 2098-2109.

Lyons, D. (1965). Forms and limits of Utilitarianism. Oxford, England: Clarendon Press.

MacIntyre, A. (2007). After virtue: A study in moral theory. (3rd ed.). Notre Dame, IN: University of Notre Dame Press.

Manski, C., \& Pepper, J. (2013). Deterrence and the death penalty: Partial identification analysis using repeated cross sections. Journal of Quantitative Criminology, 29(1), 123141.
O’Neil, K., Patry, M., \& Penrod, S. (2004). Exploring the effects of attitudes toward the death penalty on capital sentencing verdicts. Psychology, Public Policy, and Law, 10(4), 443-470.

Powell, D., Weisman, K., \& Markman, E. M. (2018). Articulating lay theories through graphical models: A study of attitudes surrounding vaccination decisions. Proceedings of the 40th Annual Conference of the Cognitive Science Society, 906-911.

Rawls, J. (1980). Kantian Constructivism in moral theory. The Journal of Philosophy, 77(9), 515-572.

Roberts, J., \& Stalans, L. (1997). Public opinion, crime, and criminal justice. Boulder, CO: Westview Press.

Rouder, J. (2014). Optional stopping: No problem for Bayesians. Psychonomic Bulletin \& Review, 21(2), 301308.

Sen, A., \& Williams, B. (1982). Utilitarianism and beyond. Cambridge, England: Cambridge University Press.

Thaler, R., \& Sunstein, C. (2008). Nudge: Improving decisions about health, wealth, and happiness. New Haven, CT: Yale University Press. 